OPEN ACCESS

Edited by:

Oana Moldovan,

Emil Racovita Institute of Speleology,

Romania

Reviewed by:

Søren Toft,

Aarhus University, Denmark

Alistair McNair Senior

University of Sydney, Australia

*Correspondence:

Shawn M. Wilder

shawn.wilder@okstate.edu

Specialty section:

This article was submitted to Biogeography and Macroecology,

a section of the journal

Frontiers in Ecology and Evolution

Received: 08 November 2018

Accepted: 05 February 2019

Published: 27 February 2019

Citation:

Wilder SM, Barnes CL and Hawlena D (2019) Predicting Predator Nutrient Intake From Prey Body Contents. Front. Ecol. Evol. 7:42

doi: 10.3389/fevo.2019.00042

\section{Predicting Predator Nutrient Intake From Prey Body Contents}

\author{
Shawn M. Wilder ${ }^{1 *}$, Cody L. Barnes ${ }^{1}$ and Dror Hawlena ${ }^{2}$ \\ ${ }^{1}$ Department of Integrative Biology, Oklahoma State University, Stillwater, OK, United States, ${ }^{2}$ Risk-Management Ecology \\ Lab, Department of Ecology, Evolution and Behavior, Alexander Silberman Institute of Life Sciences, The Hebrew University \\ of Jerusalem, Jerusalem, Israel
}

Predator-prey interactions can have important consequences for the flow of nutrients through food webs and ecosystems. Given the diversity of predator-prey interactions, it is infeasible to directly measure predator nutrient intake when feeding on each potential prey. Elements are an important measure of nutrient flow through food webs but do not fully account for variation in the quality of nutrients in which they are present. The overall goal of this study was to test if measures of macronutrients, metabolizable protein and lipid, could be used to improve measures of elemental ingestion by predators when feeding on prey. This experiment used two prey that differed widely in exoskeleton content (i.e., larval vs. adult mealworms) because arthropod prey vary widely in this trait and it has the potential to complicate nutritional measurements since it contains nitrogen but is indigestible to most predators. Our results show that the elemental content of whole prey was a poor predictor of elemental consumption by predators. Macronutrient content of whole prey was a strong predictor of macronutrient ingestion by predators, which suggested that it may be a useful measure of predator consumption. Using macronutrient data to create a hybrid element-macronutrient measure of whole prey resulted in better predictions of total elemental ingestion by predators. These results suggest that combining elemental and macronutrient approaches in the study of trophic transfers of nutrients, especially during predator-prey interactions, has the potential to increase our ability to understand and predict the flow of nutrients through food webs and ecosystems.

\section{Keywords: prey, predator, nutrition, elements, macronutrients}

\section{INTRODUCTION}

Food webs describe the network of feeding interactions in ecological communities (McCann, 1996; Polis and Winemiller, 1996; Thompson et al., 2012). At each consumer-resource interaction, a fraction of the resources is transferred to the consumer as new biomass while the remaining resources are released into the environment (i.e., respiration, egestion, and excretion). Understanding the efficiency through which nutrients (i.e., including molecules and the elements contained therein) are assimilated vs. respired/excreted/egested by consumers is critical for understanding and modeling the pathways through which nutrients flow through ecosystems (McCann, 1996; Polis and Winemiller, 1996; Thompson et al., 2012). Given the complexity of most food webs, it is not feasible to empirically study each pairwise trophic interaction. Hence, it is important to develop methods that can be used to predict the fates (e.g., assimilation, excretion) of nutrients during trophic interactions. 
Elements have been the primary currency used to follow the flow of nutrients through food webs and ecosystems. Elements are a useful currency because they cannot be broken down and, hence,allow for the use of mass balance approaches to studying the flow of nutrients (Sterner and Elser, 2002). Particular elements are often assumed to be associated with molecules that can limit growth, reproduction, or other measures of fitness in animals (e.g., macronutrients, nucleic acids) (Fagan et al., 2002; Sterner and Elser, 2002). However, a constraint on using elements is that elements alone do not provide any information on the quality or digestibility of the molecules in which they are found (Bell, 1990; Mitra and Flynn, 2005; Wilder and Eubanks, 2010). This is especially problematic when significant amounts of elements are contained in non-metabolizable, structural tissues of food items (Klowden, 2007; Chapman, 2013). For example, studies of terrestrial trophic dynamics sometimes distinguish between structural (e.g., cellulose, lignin) and non-structural (e.g., sugar, starch) carbohydrates as both have nearly identical elemental composition but differ dramatically in digestibility for most herbivores (Lincoln et al., 1993). Similar problems may exist for terrestrial predator-prey interactions as significant amounts of $\mathrm{N}$ and $\mathrm{P}$ may be bound in indigestible exoskeleton or skeleton, respectively (Evans, 1938; Finke, 2007; Chapman, 2013). Yet, it remains unclear whether or not distinguishing between structural and non-structural molecules in prey would aid in understanding the transfer of nutrients from prey to predator.

Arthropods constitute a large amount of the biomass of food webs and are abundant and common prey for a wide range of predators including both invertebrates and vertebrates (Bell, 1990; Mooney et al., 2010). Exoskeleton is a key trait of arthropods and the amount of exoskeleton can vary widely among species (e.g., 18-60\% of dry mass; Kaspari and Joern, 1993; Lease and Wolf, 2010). While exoskeleton is commonly regarded as a chitin-rich compound, it can contain significant amounts of non-metabolizable protein (e.g., up to half by mass) that are bound within the chitin matrix to increase strength of the exoskeleton (Klowden, 2007; Chapman, 2013). Exoskeleton is indigestible to the majority of predators (e.g., excluding seabirds, Weiser et al., 1997; Finke, 2007). Yet, it is not uncommon for studies of the quality of arthropods as prey to quantify total nutrient content of prey bodies (e.g., total $\mathrm{C}$ and $\mathrm{N}$ content of arthropods) without differentiating between digestible nutrients in soft tissue and indigestible nutrients in exoskeleton (Wilder and Eubanks, 2010; Wilder, 2011). Measures of nutrients that do not account for exoskeleton content of prey may not provide an accurate measure of nutrients available to predators (Bell, 1990; Wilder and Eubanks, 2010; Jonas-Levi and Martinez, 2017).

The overall goal of this study was to test if combining elemental and macronutrient data could improve predictions of the transfer of nutrients from prey to predator during predation. Metabolizable protein and exoskeleton are two abundant tissues in arthropods and both can contain significant amounts of carbon and nitrogen. Lipid is also an important nutrient for predators and source of carbon. When spiders and many other predators feed on arthropod prey, the macronutrients present in prey are digested while the exoskeleton is discarded. Hence, we predicted that estimates of the $\mathrm{C}$ and $\mathrm{N}$ present in the macronutrients of prey (i.e., lipid and metabolizable protein) would be a better measure of the amount of $\mathrm{C}$ and $\mathrm{N}$ ingested by predators than would the total elemental content of prey, which includes both macronutrients and exoskeleton. Identifying a measure of prey that predicts predator nutrient ingestion will aid in better understanding and modeling the flow of nutrients through food webs and ecosystems without having to conduct feeding trials on every potential prey item.

For this study, we used two prey of the same species that differed significantly in exoskeleton content: larval and adult mealworm beetles (Tenebrio molitor). Our analyses included prey treatment (larval vs. adult beetle) and nutrient category (nutrients present vs. nutrients ingested) and their interaction as main effects. This type of analysis was used rather than ratios or proportion of nutrients ingested given the statistical problems associated with analyzing ratios (Raubenheimer and Simpson, 1992; Raubenheimer, 1995). Presenting results in this way also provides a clear comparison between what is present in whole prey and what is actually consumed by a predator feeding on that prey. A significant interaction effect would indicate that the proportion of nutrients ingested from prey differed by prey type.

\section{METHODS}

\section{Study Species}

Mealworm (T. molitor) larvae were purchased (Fluker Farms, Louisiana) and used to create a breeding population in the lab that produced a constant supply of larvae and adults. The mealworm colony was maintained on a diet of wheat germ and provided potatoes as a source of water. The colony was maintained on a 14L:10D light regime at constant $25 \pm 1^{\circ} \mathrm{C}$.

Female wolf spiders (Hogna carolinensis) were collected from mowed fields in Stillwater, Oklahoma during summer 2016. The spiders were maintained on a $14 \mathrm{~L}: 10 \mathrm{D}$ light regime at a constant $25 \pm 1^{\circ} \mathrm{C}$ in the lab. They were lightly misted with water and fed crickets (Acheta domesticus) twice per week. The spiders were housed in $1,420 \mathrm{~mL}$ (48oz), clear plastic containers.

\section{Feeding Trials}

Our study used a standardized starvation period to clear the spider gut of previous meals and to ensure that spiders were motivated to consume all of the edible tissue from prey. Spiders were fasted for 14 days prior to each feeding trial. In the field, spiders often experience starvation periods greater than 1 week (Bilde and Toft, 1998). Data on another species of wolf spider also suggest that they are frequently food limited in nature as body condition of individuals collected from the field was not significantly different from laboratory individuals that were completely deprived of food for 3 months (Wilder and Rypstra, 2008). Hence, this starvation period was appropriate for studying nutrient transfer during trophic interactions involving spiders and other food-limited predators. Future studies of trophic transfer by other organisms should adjust laboratory feeding regimes to be similar to those experienced by animals in nature.

On day 9 of the fast, we transferred spiders to $946 \mathrm{~mL}$ respiration chambers, measured spider body masses $( \pm 1 \mathrm{mg})$, and ordered them by mass. Even numbers were assigned to 
mealworm larvae and odd numbers were assigned to adult beetle treatment groups. This assignment ensured similarity of spider mass between prey treatment groups.

Following the 14-day fasting period, spiders were fed a single pre-weighed prey item (i.e., larval or adult beetle). Each spider was only used once and there were 9 spiders each in the larvae and adult beetle treatments. We controlled for prey mass such that the average wet mass of larvae $(80.9 \pm 3.2 \mathrm{mg})$ and beetles $(78.0 \pm 3.1 \mathrm{mg})$ were not significantly different $\left[t_{(1,27)}=0.65\right.$, $p=0.52]$. Meal size (i.e., prey mass relative to the spider mass) also did not differ between treatments [larvae: $25.8 \pm 1.9 \%$ and beetles: $24.0 \pm 1.8 \%$ of the spider mass; $t_{(1,27)}=70, p=0.49$ ]. The mass of late-development larval insects such as mealworms is often similar to or larger than that of recently eclosed adults as metamorphosis involves the metabolism of a significant amount of energy reserves.

During feeding trials, spiders were observed every $3 \mathrm{~h}$ and the time at which prey were discarded was recorded. All spiders had finished feeding by $9 \mathrm{~h}$. At this time the discarded prey remains were removed and weighed. Spiders generally captured prey within $30 \mathrm{~s}$, completed extra-oral digestion in $6 \mathrm{~h}$, and produced most of their excreta within $24 \mathrm{~h}$.

\section{Nutritional Analyses}

We froze the whole prey and prey remains until analyses. Whole prey and remains were then dried at $60^{\circ} \mathrm{C}$ for $24 \mathrm{~h}$, bisected to produce two equal portions, and weighed. Then, each half was randomly assigned to either macronutrient or elemental analysis.

We measured lipid content as the change in mass of the dry prey following sequential soaking and extraction in chloroform over the course of 3 days (Wilder et al., 2013). Metabolizable protein content was measured in triplicates using the Bradford Assay modified for use in 96-well microplates on lean, ground samples (Wilder et al., 2013). In preparation for the Bradford Assay, subsamples of prey were treated with $0.1 \mathrm{M}$ sodium hydroxide, which readily dissolves soft tissues but cannot dissolve exoskeleton. Hence, protein analysis using the Bradford Assay on these samples only measured the metabolizable protein present in the soft tissues of the prey (Wilder et al., 2013). Exoskeleton can have considerable protein content; however, proteins present within the exoskeleton are non-metabolizable and, hence, unavailable to consumers because they are bound within the inedible matrix of chitin (Klowden, 2007; Chapman, 2013). Hence, non-metabolizable proteins bound in the exoskeleton are not included in our measures of metabolizable protein. Carbohydrates were not measured as they are typically present at low levels in arthropods (Raubenheimer and Rothman, 2013).

Measurements of carbon and nitrogen content were taken on lipid-extracted whole prey, lipid from prey, and uneaten remains of prey. We removed lipid from prey items before elemental analysis because high lipid content of prey, especially mealworm larvae, can make it difficult to homogenize samples into a powder. Hence, to calculate total carbon content of whole prey we also measured the carbon content of the purified lipids that were extracted from prey and factored this back in to the calculation of prey total carbon content based on the lipid content of the prey. To measure purified lipids, we placed all chloroform used in the lipid extraction procedure into a glass beaker, evaporated the chloroform, and sampled the lipid residue. The $\mathrm{C}$ and $\mathrm{N}$ in samples were quantified by combustion in an elemental analyzer (Elementar Americas, Inc., Mt. Laurel, New Jersey). We calculated nutrient ingestion by spiders as the difference between what was present in whole prey items and what was left over in the uneaten prey remains. We used wet mass and nutrient content of control larvae and beetles to develop linear regression equations to predict the mass of nutrients present in the whole prey that were fed to spiders. From the linear equations, we were able to use the wet mass of prey fed to spiders to estimate the masses of each nutrient contained in the prey before it was fed to a spider.

Elements and macronutrients are two direct measures of prey nutrient content. We also calculated hybrid measures of the elemental content of the macronutrient portion of each prey for both carbon and nitrogen. Measures of elements found in macronutrients of whole prey were compared with total elemental ingestion by predators. These allowed us to test if measures of only those elements found in the macronutrient portions of prey were better predictors of total elemental ingestion than all elements found in prey. For carbon, we calculated "macronutrient-based C" as the amount of carbon present in the lipid and metabolizable protein tissues of prey based on the mass and carbon content of lipid and metabolizable protein in prey. The carbon content of lipid was measured as part of this study and the carbon content of metabolizable protein (53\%) was taken from the literature (Rouwenhorst et al., 1991). For nitrogen, we calculated "macronutrient-based N" as the metabolizable protein present in prey multiplied by 0.118 , as our empirical data showed that $11.8 \pm 0.05 \%$ of lean (i.e., lipid free) mealworm tissue (larvae $=11.78 \pm 0.08$; adults $=$ $11.83 \pm 0.06)$ was nitrogen. It is commonly assumed that protein has an average $\mathrm{N}$ concentration of $16 \%$ (Jones, 1941). However, the $\mathrm{N}$ content of individual amino acids varies from 8 to $32 \%$ and, hence, the $\mathrm{N}$ content of proteins will vary depending upon their amino acid composition. Two-factor analysis of variance (ANOVA) with prey type (larvae vs. adult), nutrient type (present in whole prey vs. ingested), and the interaction was used to analyze nutrient measures.

\section{RESULTS}

For prey dry mass, there was a significant interaction between prey type (larval vs. adult beetle) and nutrient category (nutrients present vs. ingested) (Table 1, Figure 1). While there was no difference in the dry mass present in whole larval and adult mealworms, there was a significant difference in the amount of dry mass consumed by spiders feeding on the two prey types. Spiders consumed $86 \%$ of the dry mass of larvae but only $51 \%$ of the dry mass of adult beetles.

There were also significant interaction effects for total carbon and total nitrogen (Table 1, Figure 2). There was significantly more total carbon present in the whole bodies of larvae than adults. Spiders also ingested significantly more carbon when feeding on larvae than adults. In addition, spiders ingested a significantly higher proportion of the total carbon of larvae (89\%) than adult beetles (60\%), which explains the significant interaction term (Figure 2A). For total nitrogen, adult 
TABLE 1 | Results of the statistical analysis (2-factor analysis of variance) comparing nutrients present in whole prey bodies with nutrients ingested by predators feeding on those prey for larval and adult mealworm beetles.

\begin{tabular}{|c|c|c|c|c|c|c|c|}
\hline & \multirow[b]{2}{*}{$d f$} & \multicolumn{2}{|c|}{ Prey type (Larvae vs. Adult) } & \multicolumn{2}{|c|}{ Nutrient category (Present vs. Ingested) } & \multicolumn{2}{|c|}{ Interaction } \\
\hline & & $\boldsymbol{F}$ & $p$ & $\boldsymbol{F}$ & $p$ & $\boldsymbol{F}$ & $p$ \\
\hline Dry Mass & 1,32 & 42.8 & $<0.001$ & 101.0 & $<0.001$ & 29.4 & $<0.001$ \\
\hline Carbon & 1,29 & 95.9 & $<0.001$ & 134.3 & $<0.001$ & 40.7 & $<0.001$ \\
\hline Nitrogen & 1,29 & 10.8 & $<0.001$ & 183.0 & $<0.001$ & 50.9 & $<0.001$ \\
\hline Lipid & 1,32 & 1362.7 & $<0.001$ & 2.0 & 0.17 & 0.1 & 0.85 \\
\hline Protein & 1,31 & 215.7 & $<0.001$ & 11.1 & 0.002 & 0.9 & 0.35 \\
\hline Macronutrient- $\mathrm{C}^{\star}$ & 1,29 & 380.7 & $<0.001$ & 18.1 & $<0.001$ & 7.5 & 0.01 \\
\hline Macronutrient- $\mathrm{N}^{\wedge}$ & 1,26 & 50.0 & $<0.001$ & 3.6 & 0.07 & 11.8 & 0.002 \\
\hline
\end{tabular}

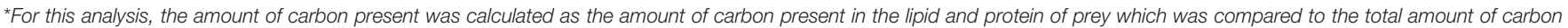

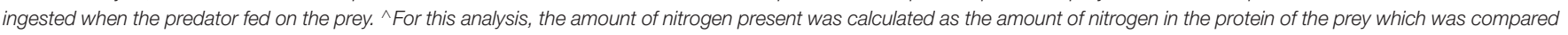
to the total amount of nitrogen ingested when the predator fed on the prey.

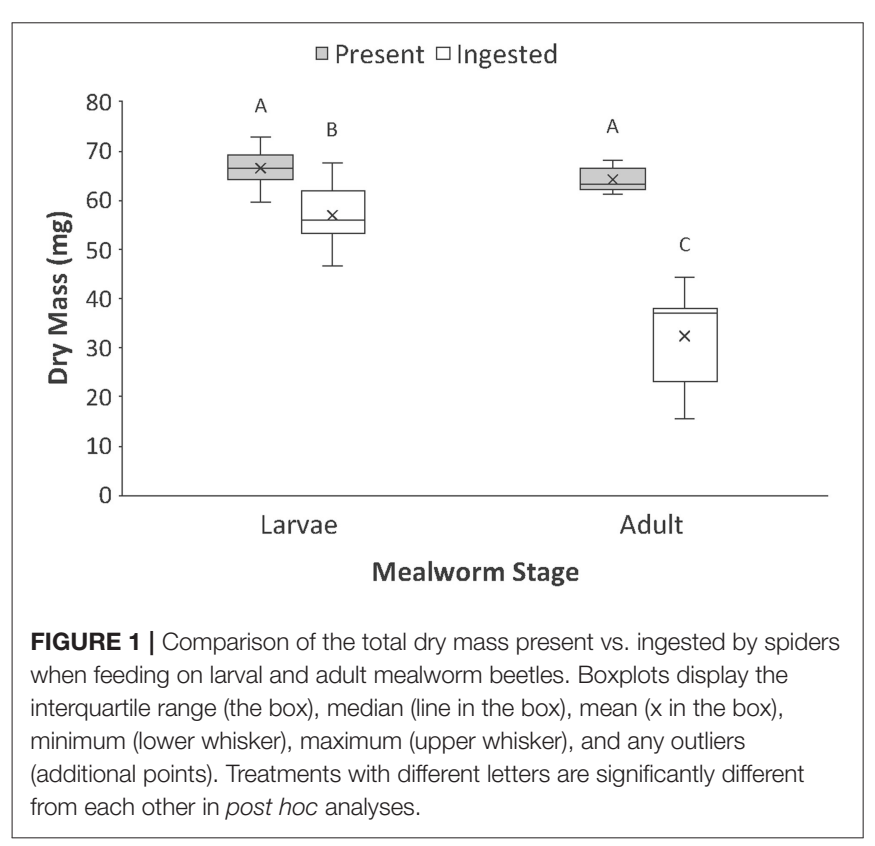

mealworms had significantly higher total nitrogen content in their bodies than larvae but spiders ingested significantly more nitrogen when feeding on larvae than adult beetles (Figure 2B). This was because spiders ingested a much higher proportion of nitrogen in larvae (83\%) than adult beetles (56\%).

In contrast to dry mass, total carbon and total nitrogen, the macronutrient content of whole larval and adult mealworm bodies was a strong predictor of macronutrients ingested by spiders (Table 1, Figure 3 ). There was significantly more lipid present in larval than adult mealworm beetles. However, there was no significant difference between the amount of nutrients present and the amounts ingested, which means that spiders ingested nearly all the lipid present in prey bodies (Figure 3A). There was no interaction between prey treatment and nutrient category for lipid. For metabolizable protein, there was significantly more protein in larval than adult mealworm beetles. However, unlike lipid, there was also a significant effect of nutrient category, which indicates that spiders did not extract all of the metabolizable protein present in prey. Yet, there was no interaction between prey type and nutrient category, which indicates that the proportion of metabolizable protein that spider consumed from larval (95\%) and adult beetles (86\%) was not significantly different (Figure 3B).

We then calculated the mass of carbon present in the metabolizable protein and lipid tissues of each whole prey (macronutrient-based C) and compared that with the total mass of carbon ingested from each prey (Table 1, Figure 4A). There was a significant interaction between prey type and nutrient category. For adult beetles, the total mass of carbon ingested by spiders was not significantly different from the mass of carbon present in the lipid and metabolizable protein tissues of the beetle. However, for larval mealworms, the total amount of carbon ingested by spiders was slightly but significantly less than the total amount of carbon estimated to be present in the lipid and metabolizable protein tissues of the larval mealworm.

We also calculated the mass of nitrogen present in the metabolizable protein tissue of each prey (macronutrient-based N) and compared that with the total mass of nitrogen ingested from each prey (Table 1; Figure 4B). There was a significant interaction between prey type and nutrient category. The total mass of nitrogen ingested by predators feeding on adult beetles was not significantly different from the amount of nitrogen estimated to be in the metabolizable protein tissues of the adult beetles. However, for larval mealworms, the total amount of nitrogen ingested by spiders was slightly but significantly less than the total amount of nitrogen estimated to be present in the metabolizable protein tissues of the larval mealworm.

\section{DISCUSSION}

Given the diversity of pairwise trophic interactions in food webs, it would be useful to have a way of predicting predator nutrient intake based solely on the body composition of prey without having to perform feeding assays with each potential prey item. Our results demonstrate that the total elemental (carbon and nitrogen) content of prey is a poor predictor of the amounts of elements ingested by predators feeding on those prey. When we combined elemental and macronutrient currencies, our results show that macronutrient-based $\mathrm{C}$ and $\mathrm{N}$ in whole prey were better than elements alone at predicting $\mathrm{C}$ and $\mathrm{N}$ consumption 


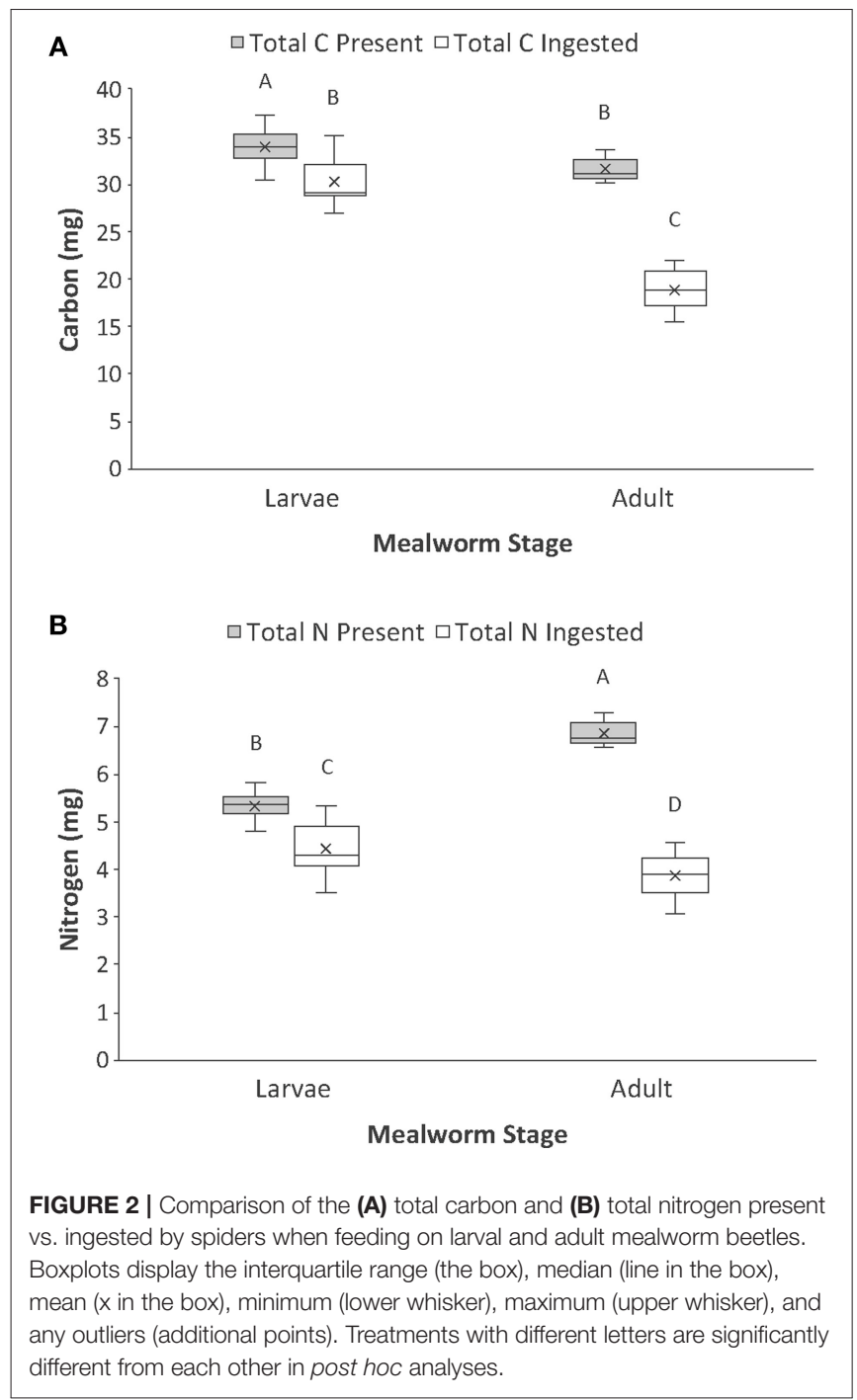

by predators. These results provide evidence that combining macronutrient and elemental perspectives may provide a more accurate understanding of the trophic transfer of nutrients from prey to predators. Further refining macronutrient-based elemental measures may provide an even better ability to predict trophic transfers of nutrients during predator-prey interactions.

The data on $\mathrm{N}$ presence vs. ingestion provided some of the most striking data that total elemental content of prey can be a poor predictor of elemental consumption by predators. Adult beetles had significantly more nitrogen in their bodies than larvae but spiders ingested significantly more nitrogen when feeding on larvae relative to adults. This is likely because, while adult mealworm beetles had significantly more $\mathrm{N}$ than larvae, the adults also had significantly less metabolizable protein than larvae and metabolizable protein is the primary form of $\mathrm{N}$ that is ingested by predators. As a result, the common assumption that $\mathrm{N}$ content is a predictor of metabolizable protein content is not supported in this system (e.g., the assumption that protein $=\mathrm{N} \times$ 6.25) (Jones, 1941; Sterner and Elser, 2002). Opposing patterns of $\mathrm{N}$ and metabolizable protein in larvae

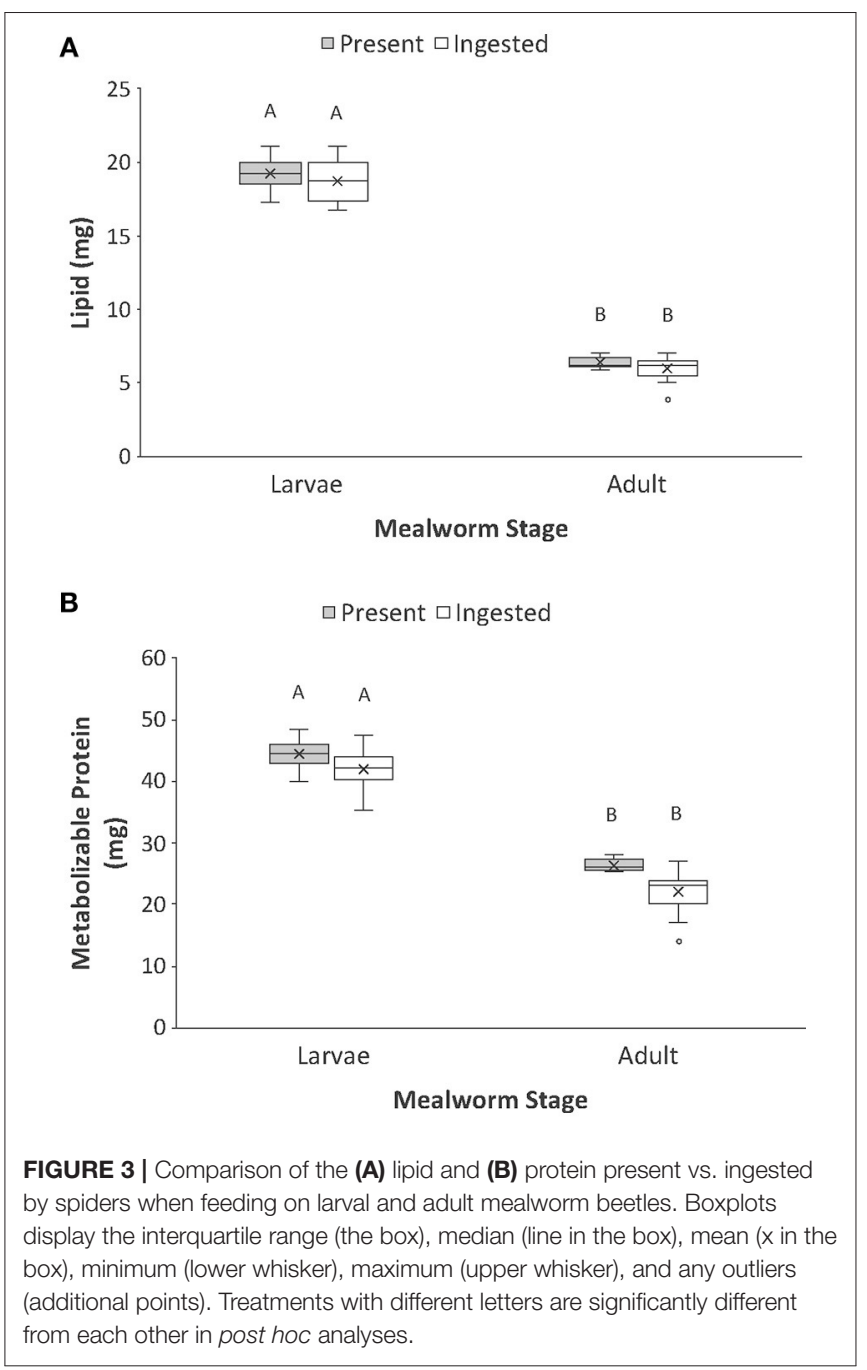

vs. adults is likely due to the large differences in indigestible exoskeleton content of larval (i.e., more metabolizable protein and less exoskeleton) and adult (i.e., less metabolizable protein and more exoskeleton) mealworms.

Exoskeleton can contain significant amounts of nonmetabolizable proteins (i.e., up to half the mass of exoskeleton; Klowden, 2007; Chapman, 2013) that are bound within a chitin matrix. The non-metabolizable proteins in the exoskeleton of prey are not digested by predators or by the chemicals used in the protein assay protocol (i.e., the protein assay only measures protein in the soft tissues of prey). Exoskeleton is a key molecule that can decouple the relationship between $\mathrm{N}$ and metabolizable protein. Given the wide variation in the exoskeleton content of arthropod species, it is likely that $\mathrm{N}$ is a poor predictor of metabolizable protein content of arthropods and the amounts of metabolizable protein or $\mathrm{N}$ ingested by predators feeding on arthropods more generally. Further work conducting feeding assays on a wider range of arthropod prey is needed to better understand which measures of whole prey best predict the amounts of nutrients transferred to predators feeding on those prey. 


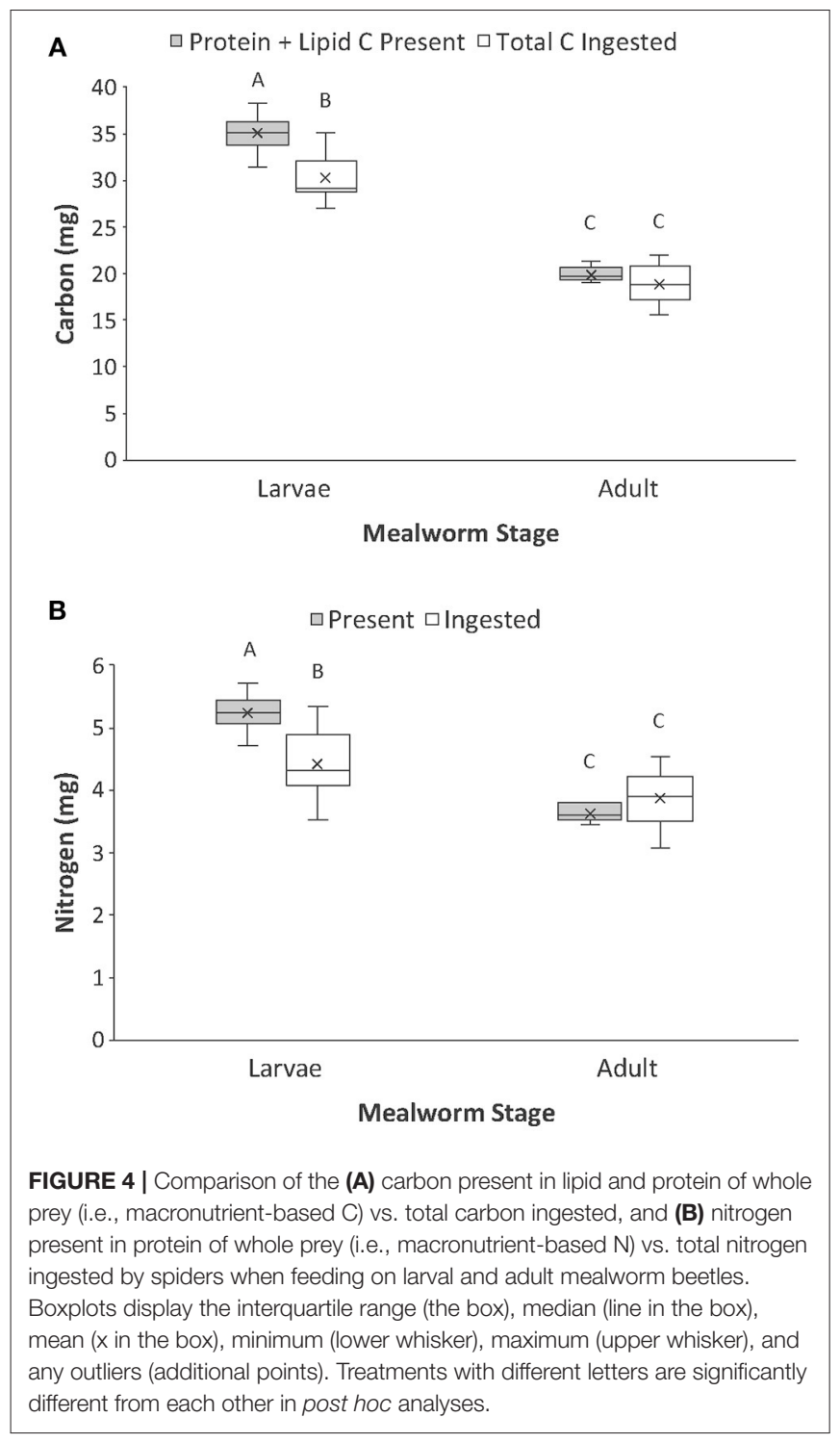

Macronutrient-based $\mathrm{C}$ and $\mathrm{N}$ in prey bodies was a closer approximation of the total amount of nutrients ingested by predators than was the total elemental content of the prey (i.e., compare Figures 2, 4). But, macronutrient-based $\mathrm{C}$ and $\mathrm{N}$ in prey were still not perfect measures of total $\mathrm{C}$ and $\mathrm{N}$ consumption by predators. One factor that may explain the lack of perfect correspondence between the measures is that we did not measure all digestible sources of $\mathrm{C}$ and $\mathrm{N}$ in prey. There are a range of other common biomolecules that could have contributed to digestible sources of $\mathrm{C}$ and $\mathrm{N}$, the most abundant of which may include carbohydrates (e.g., glycogen, trehalose) and nucleic acids (e.g., DNA, RNA). It remains unknown if quantification of these additional molecules would improve predictions of nutrient transfers during predator-prey interactions. There are likely declining benefits of increasing the resolution of chemical analyses. The measures of lipid and metabolizable protein used in the present study were relatively simple and inexpensive measures of prey that, when conducted in addition to standard elemental analysis, appeared to have a significant benefit for predicting predator nutrient intake. Yet, further work is needed to test whether adding even more detailed chemical analyses would improve the accuracy of macronutrient-based $\mathrm{C}$ and $\mathrm{N}$ measures enough to justify the increased time and cost of these analyses.

The ecological importance of studying the trophic transfer of nutrients from prey to predators was highlighted in a series of studies that compared elemental content of arthropod herbivores and predators (Fagan et al., 2002; Denno and Fagan, 2003; Fagan and Denno, 2004). These studies documented significantly higher $\mathrm{N}$ and lower C:N in predators relative to herbivores. Based on these differences, it was argued that predators may be $\mathrm{N}$-limited and motivated to engage in intraguild predation to increase the $\mathrm{N}$ content of their diet (Denno and Fagan, 2003). A later study of elements and macronutrients in arthropod food webs confirmed higher $\mathrm{N}$ content in predatory arthropods but also found that predators had lower lipid content than herbivores (Wilder et al., 2013). Based on these findings, the high $\mathrm{N}$ content of predators appears to be a result of predators having low lipid reserves due to frequent food or energy limitation (Wilder and Eubanks, 2010; Wilder et al., 2013). The differences between these two studies suggests that another potential benefit of measuring both currencies is that macronutrients may provide a better understanding of the mechanisms contributing to patterns of elemental variation among individuals or taxa that may aid in understanding the ecological consequences of these patterns in elements (Wilder and Eubanks, 2010; Wilder and Jeyasingh, 2016; Zhang et al., 2016).

Overall, our results suggest that macronutrient-based measures of $\mathrm{C}$ and $\mathrm{N}$ in animals may improve predictions of the trophic transfer of nutrients during predator-prey interactions compared to estimates based on elements alone. Yet, challenges remain, including identifying the mechanism responsible for the lack of correspondence between total elemental content of prey and elemental ingestion by predators (e.g., variation among species in exoskeleton), and testing whether these results represent a general pattern in arthropod predator-prey interactions. Furthermore, it remains unclear if future studies of trophic transfers of nutrients in arthropod predator-prey interactions need to examine each prey taxa separately or if general scaling relationships can be made based on factors such as prey size (e.g., Lease and Wolf, 2010, 2011). Improving the accuracy of estimates of trophic transfers of nutrients during predator-prey interactions should aid in better understanding, predicting, and modeling the flow of energy and materials through food webs and the consequences of these flows for community and ecosystem function.

\section{AUTHOR CONTRIBUTIONS}

SW, CB, and DH contributed to the conception and design of the study and writing of the manuscript. CB conducted the experiments and collected data. SW analyzed the data.

\section{FUNDING}

This research was supported by Oklahoma State University, and the National Science Foundation (DEB1838988 to SW). 


\section{REFERENCES}

Bell, G. P. (1990). Birds and mammals on an insect diet: a primer on diet composition analysis in relation to ecological energetics. Studies Avian Biol. 13, 416-422.

Bilde, T., and Toft, S. (1998). Quantifying food limitation of arthropod predators in the field. Oecologia 115, 54-58. doi: 10.1007/s004420050490

Chapman, R. F. (2013). The Insects: Structure and Function. New York, NY: Cambridge University Press.

Denno, R. F., and Fagan, W. F. (2003). Might nitrogen limitation promote omnivory among carnivorous arthropods? Ecology 84, 2522-2531. doi: 10.1890/02-0370

Evans, A. C. (1938). Physiological relationships between insects and their host plants. Ann. Appl. Biol. 25, 558-572. doi: 10.1111/j.1744-7348.1938.tb04369.x

Fagan, W. F., and Denno, R. F. (2004). Stoichiometry of actual vs. potential predator-prey interactions: insights into nitrogen limitation for arthropod predators. Ecol. Lett. 7, 876-883. doi: 10.1111/j.1461-0248.2004. 00641.x

Fagan, W. F., Siemann, E., Mitter, C., Denno, R. F., Huberty, A. F., Woods, H. A., et al. (2002). Nitrogen in insects: implications for trophic complexity and species diversification. Am. Naturalist. 160, 784-802. doi: 10.1086/343879

Finke, M. D. (2007). Estimate of chitin in raw whole insects. Zoo Biol. 26, 105-115. doi: 10.1002/zoo.20123

Jonas-Levi, A., and Martinez, J. I. (2017). The high level of protein content reported in insects for food and feed is overestimated. J. Food Comp. Anal. 62, 184-188. doi: 10.1016/j.jfca.2017.06.004

Jones, D. B. (1941). Factors For Converting Percentages of Nitrogen in Foods and Feeds Into Percentages of Proteins. Washington, DC: US Department of Agriculture.

Kaspari, M., and Joern, A. (1993). Prey choice by three insectivorous grassland birds: reevaluating opportunism. Oikos 68, 414-430. doi: 10.2307/3544909

Klowden, M. (2007). Physiological Systems in Insects. San Francisco, CA: Academic Press.

Lease, H. M., and Wolf, B. O. (2010). Exoskeletal chitin scales isometrically with body size in terrestrial insects. J. Morphol. 271, 759-768. doi: $10.1002 /$ jmor. 10835

Lease, H. M., and Wolf, B. O. (2011). Lipid content of terrestrial arthropods in relation to body size, phylogeny, ontogeny and sex. Physiol. Entomol. 36, 29-38. doi: $10.1111 /$ j.1365-3032.2010.00767.x

Lincoln, D. E., Fajer, E. D., and Johnson, R. H. (1993). Plant-insect herbivore interactions in elevated $\mathrm{CO}_{2}$ environments. Trends Ecol. Evol. 8, 64-68. doi: 10.1016/0169-5347(93)90161-H

McCann, K. S. (1996). Food Webs. Princeton University Press.

Mitra, A., and Flynn, K. J. (2005). Predator-prey interactions: is 'ecological stoichiometry' sufficient when good food goes bad? J. Plankton Res. 27, 393-399. doi: 10.1093/plankt/fbi022

Mooney, K. A., Gruber, D. S., Barber, N. A., Van Bael, S. A., Philpott, S. M., and Greenberg, R. (2010). Interactions among predators and the cascading effects of vertebrate insectivores on arthropod communities and plants. Proc. Natl. Acad. Sci. U.S.A. 107, 7335-7340. doi: 10.1073/pnas.10019 34107
Polis, G. A., and Winemiller, K. O. (1996). Food Webs. Springer Press.

Raubenheimer, D. (1995). Problems with ratio analysis in nutritional studies. Funct. Ecol. 9, 21-29. doi: 10.2307/2390086

Raubenheimer, D., and Rothman, J. M. (2013). Nutritional ecology of entomophagy in humans and other primates. Annu. Rev. Entomol. 58, 141-160. doi: 10.1146/annurev-ento-120710-100713

Raubenheimer, D., and Simpson, S. J. (1992). Analysis of covariance: an alternative to nutritional indices. Entomol. Exp. Appl. 62, 221-231. doi: 10.1111/j.1570-7458.1992.tb00662.x

Rouwenhorst, R. J., Jzn, J. F., Scheffers, W. A., and van Dijken, J. P. (1991). Determination of protein concentration by total organic carbon analysis. J. Biochem. Biophys. Methods 22, 119-128. doi: 10.1016/0165-022X(91) 90024-Q

Sterner, R. W., and Elser, J. (2002). Ecological Stoichiometry. Princeton, NJ: Princeton University Press.

Thompson, R. M., Brose, U., Dunne, J. A., Hall, R. O., Hladyz, S., Kitching, R. L., et al. (2012). Food webs: reconciling the structure and function of biodiversity. Trends Ecol. Evolut. 27, 689-697. doi: 10.1016/j.tree.2012.08.005

Weiser, J. I., Porth, A., Mertens, D., and Karasov, W. H. (1997). Digestion of chitin by northern bobwhites and American robins. Condor 99, 554-556. doi: $10.2307 / 1369967$

Wilder, S. M. (2011). Spider nutrition: an integrative perspective. Adv. Insect. Phys. 40, 87-136. doi: 10.1016/B978-0-12-387668-3.00002-7

Wilder, S. M., and Eubanks, M. D. (2010). Might nitrogen limitation promote omnivory among carnivorous arthropods? Comment. Ecol. 91, 3114-3117. doi: 10.1890/09-2080.1

Wilder, S. M., and Jeyasingh, P. D. (2016). Merging elemental and macronutrient approaches for a comprehensive study of energy and nutrient flows. J. Animal Ecol. 85, 1427-1430. doi: 10.1111/1365-2656.12573

Wilder, S. M., Norris, M., Lee, R. W., Raubenheimer, D., and Simpson, S. J. (2013). Arthropod food webs become increasingly lipid-limited at higher trophic levels. Ecol. Lett. 16, 895-902. doi: 10.1111/ele.12116

Wilder, S. M., and Rypstra, A. L. (2008). Sexual size dimorphism mediates the occurrence of state-dependent sexual cannibalism in a wolf spider. Anim. Behav. 76, 447-454. doi: 10.1016/j.anbehav.2007.12.023

Zhang, C., Jansen, M., Meester, L. D., and Stoks, R. (2016). Energy storage and fecundity explain deviations from ecological stoichiometry predictions under global warming and size-selective predation. J. Anim. Ecol. 85, 1431-1441. doi: $10.1111 / 1365-2656.12531$

Conflict of Interest Statement: The authors declare that the research was conducted in the absence of any commercial or financial relationships that could be construed as a potential conflict of interest.

Copyright (C) 2019 Wilder, Barnes and Hawlena. This is an open-access article distributed under the terms of the Creative Commons Attribution License (CC BY). The use, distribution or reproduction in other forums is permitted, provided the original author(s) and the copyright owner(s) are credited and that the original publication in this journal is cited, in accordance with accepted academic practice. No use, distribution or reproduction is permitted which does not comply with these terms. 